\title{
Análise econômica da terminação de novilhos em confinamento recebendo diferentes proporções de cana-de-açúcar e concentrado
}

\author{
Economic analysis of finishing feedlot steers fed different \\ proportions of sugar cane and concentrated
}

\author{
Paulo Santana Pacheco ${ }^{1 *}$; Rodrigo Medeiros da Silva²; João Teodoro Padua ${ }^{3}$; \\ João Restle ${ }^{3}$; Rodrigo Zaiden Taveira ${ }^{2}$, Fabiano Nunes Vaz ${ }^{4}$; Leonir Luiz Pascoal ${ }^{1}$; \\ Janaine Leal Olegario ${ }^{5}$; Fernanda Rezer de Menezes ${ }^{6}$
}

\section{Resumo}

Objetivou-se avaliar a economicidade da terminação em confinamento de novilhos mestiços zebuínos, recebendo dietas com 40, 60 ou $80 \%$ de concentrado (base na matéria seca), através de indicadores financeiros. Foram utilizados 30 animais com idade e peso médios iniciais de 26 meses e $348 \pm 32 \mathrm{~kg}$, respectivamente, alimentados por 90 dias, sendo abatidos com peso médio de $449 \pm 40 \mathrm{~kg}$. O delineamento experimental foi o inteiramente casualizado, com três tratamentos e dez repetições, procedendo-se análise de regressão. Houve incremento linear no custo total por animal com o aumento no nível de concentrado, oriundo das diferenças verificadas em alguns itens do custo variável, sendo que o custo com alimentação volumoso reduziu e, com a alimentação concentrado, outros e oportunidade do capital investido aumentaram com o incremento no nível de concentrado da dieta. Quanto aos indicadores financeiros, os níveis de concentrado de 40, 60 e $80 \%$ apresentaram similaridade ( $\mathrm{P}>0,05)$, sendo as estimativas médias de $\mathrm{R} \$-119,77$ para margem bruta, $\mathrm{R} \$-129,63$ para margem líquida, de $\mathrm{R} \$-162,14$ para lucro, de $\mathrm{R} \$-144,01$ para valor presente líquido, de 0,8994 para índice benefício:custo e $-10,06 \%$ para retorno adicional sobre o investimento. As estimativas foram de $-3,84 \%$ para taxa interna de retorno, de 0,1370 para relação taxa mínima de atratividade:taxa interna de retorno e 5,58 meses para payback descontado. Os indicadores financeiros evidenciaram inviabilidade econômica da terminação em confinamento, com menor retorno e maior risco conforme incrementou o nível de concentrado na dieta. Houve concordância entre os valores dos indicadores utilizados, demonstrando sua relevância na tomada de decisão.

Palavras-chave: Análise de investimentos, eficiência econômica, Nelore, projetos de investimento, tomada de decisão

\footnotetext{
Abstract

The objective of this study was to evaluate the economic viability of feedlot finishing of crossbred zebu, fed diets with 40, 60 or $80 \%$ concentrate (dry matter basis), by financial indicators. A total of 30 animals

${ }^{1}$ Profs. do Dept ${ }^{\circ}$ de Zootecnia, Universidade Federal de Santa Maria, UFSM, Santa Maria, RS. E-mail: pacheco.dz.ufsm@hotmail. com; 1lpascoal@yahoo.com.br

2 Profs. do Dept ${ }^{0}$ de Zootecnia, Universidade Estadual de Goiás, UEG, São Luís de Montes Belos, GO. E-mail: rodrigo.medeiros@, ueg.br; rodrigozaiden@gmail.com

${ }^{3}$ Profs. do Dept ${ }^{\circ}$ de Produção Animal, UFG, Goiânia, GO. E-mail: joao.teodoro@pq.cnpq.br; jorestle@terra.com.br

${ }^{4}$ Prof. do Dept ${ }^{\circ}$ de Educação Agrícola e Extensão Rural, Universidade Federal de Santa Maria, UFSM, Santa Maria, RS. E-mail: fabianonunesvaz@gmail.com

${ }^{5}$ Discente do Curso de Tecnologia em Agronegócio, UFSM, Campus Silveira Martins, Silveira Martins, RS. E-mail: janaine. agro@hotmail.com

${ }^{6}$ Discente do Curso de Graduação em Estatística, UFSM, Santa Maria, RS. E-mail: ferrezer25@hotmail.com

* Autor para correspondência
} 
with age and initial weight average of 26 months and $348 \pm 32 \mathrm{~kg}$, respectively, fed for 90 days and slaughtered at an average weight of $449 \pm 40 \mathrm{~kg}$. The experimental design was completely randomized with three treatments and ten replicates, proceeding to the regression analysis. There was a linear increase in the total cost per animal with increasing concentrate level, arising from differences in some items of variable cost, being the cost with forage feed reduced and feed concentrate, other and opportunities on invested capital increased with increase in the level of dietary concentrate. As for financial indicators, the concentrate levels of 40,60 and $80 \%$ had similar ( $P>0.05$ ), being the average estimates of $\mathrm{R} \$-119.77$ to gross margin, $\mathrm{R} \$-129.63$ to net margin, from $\mathrm{R} \$-162.14$ to profit, $\mathrm{R} \$-144.01$ to net present value, rate of 0.8994 for the benefit:cost and $-10.06 \%$ for additional return on investment. The estimates were $-3.84 \%$ for the internal rate of return, rate of 0.1370 to minimum rate of attractiveness: internal rate of return and discounted payback of 5.58 months. The financial indicators showed economic infeasibility of feedlot finishing, a lower return and higher risk with increased as the level of concentrate. There was agreement between the values of the indicators used, showing its relevance in decision making.

Key words: Investment analysis, economic efficiency, Nellore, investment projects, decision-making

\section{Introdução}

O uso do confinamento para terminação de bovinos de corte apresenta vantagens e desvantagens quando utilizada como tecnologia isolada ou agregada ao sistema de produção. Dentre algumas vantagens, destaca-se a possibilidade de adequação das dietas oferecidas aos animais, visando alterar o desempenho.

Conforme compilação de diversos estudos avaliando animais confinados, de diferentes categorias, condição sexual, composição racial, pesos de abate e idades dentro da mesma categoria (VAZ; VAZ; ROSO, 2000; RESTLE; VAZ, 2003; RESTLE; VAZ; PACHECO, 2004), a manipulação do nível de energia da dieta promove alterações no ganho de peso e conversão alimentar dos animais, e isto pode ser feito com a alteração da proporção de concentrado na dieta. No Brasil, cada vez mais vem sendo utilizadas elevadas proporções de concentrado na dieta oferecida a bovinos. Conforme pesquisa realizada por Millen et al. (2009), 77,4\% dos consultores de nutrição de confinamentos no país utilizam nível de inclusão de concentrado na dieta entre 56 e $80 \%$ (em percentagem da matéria seca) e 19,4\% utilizam entre 81 e 90\%.

No entanto, a maioria dos estudos envolvendo a terminação de bovinos em confinamento não aborda aspectos relacionados à viabilidade econômica, o que pode ser considerado uma defasagem na aplicação de um resultado técnico, do ponto de vista do produtor. Sabe-se que a resposta econômica está muito relacionada com as variações regionais, nacionais e/ou internacionais dos itens de custo, principalmente cotações do boi magro, boi gordo e alimentação, conforme demonstrado nos estudos de Resende Filho, Braga e Rodrigues (2001), Pacheco et al. (2006) e Missio et al. (2009).

Além disso, a abordagem da avaliação econômica deve, quando possível, levar em consideração indicadores técnicos de desempenho dos animais, visando proporcionar maior certeza no momento da tomada de decisão entre confinar ou não os animais.

Neste processo de tomada de decisão, Souza e Clemente (2009) sugerem a estimativa e avaliação conjunta de indicadores de retorno e de risco do investimento. $\mathrm{O}$ uso conjunto de vários indicadores resulta em informações mais consistentes do que o uso isolado de cada um deles ou de um subconjunto deles e se caracterizam pelo aprofundamento da avaliação do risco e seu confronto com a possibilidade de retorno (SOUZA; CLEMENTE, 2009). Embora utilizados com menor intensidade em estudos zootécnicos, a avaliação conjunta de indicadores de investimento apresenta facilidade metodológica, principalmente quando do uso de planilhas eletrônicas, e por consequência, facilidade na interpretação das estimativas obtidas.

Objetivou-se avaliar a viabilidade econômica do desempenho de novilhos mestiços zebuínos, 
em confinamento, recebendo dietas com 40, 60 ou $80 \%$ de concentrado, através do uso de indicadores financeiros considerando apenas o período de confinamento, sem relacioná-lo com o manejo de ciclo completo.

\section{Material e Métodos}

O experimento foi conduzido no município de São Luís de Montes Belos-GO, a 140 km da capital Goiânia, localizado no Centro Goiano do estado, a $620 \mathrm{~m}$ de altitude. Segundo classificação de Köppen (1948), a região apresenta clima tropical de savana do tipo Aw, com chuvas concentradas no verão (outubro-abril) e estação seca no inverno (maiosetembro).

Foram utilizados 30 animais mestiços zebuínos (predominância Nelore), contemporâneos e provenientes do mesmo rebanho, inteiros e com idade e peso médios de 26 meses e $348 \pm 32 \mathrm{~kg}$, respectivamente. No período anterior ao início da fase de terminação, os animais foram recriados em pastagem de Brachiaria brizantha cv. Marandu, recebendo suplementação mineral completa comercial.

A oferta de alimentos ocorreu às 6:30h e 18:30h, tendo livre acesso à água e ao alimento (volumoso + concentrado) durante todo o dia. O consumo voluntário da ração foi registrado diariamente, através da pesagem da quantidade de alimento oferecido e das sobras de alimento do dia anterior. A oferta de alimento foi estipulada em 10\% acima do consumo voluntário, sendo regulada de acordo com o consumo do dia anterior.

A composição bromatológica e proporção dos ingredientes da dieta constam na Tabela 1 . Objetivou-se ganho de peso médio de $1,2 \mathrm{~kg} / \mathrm{animal} /$ dia. Avaliaram-se três proporções de concentrado na dieta, com base na matéria seca: 40,60 ou $80 \%$. O período de alimentação foi de 90 dias, sendo os animais abatidos com idade e peso médios de 29 meses e $449 \pm 39 \mathrm{~kg}$, respectivamente, em matadourofrigorífico sob Inspeção Federal no município de Senador Canedo-GO, seguindo normas preconizadas pelo Regulamento de Inspeção Industrial e Sanitária de Produtos de Origem Animal (RIISPOA).

Tabela 1. Análise bromatológica e proporção dos ingredientes (base matéria seca) das dietas experimentais.

\begin{tabular}{lccc}
\hline \multirow{2}{*}{ Variável } & \multicolumn{3}{c}{ Nível de concentrado, \% da MS } \\
\cline { 2 - 4 } & 40 & 60 & 80 \\
\hline Umidade & 56,30 & 49,40 & 39,30 \\
Ca & 0,47 & 0,52 & 0,41 \\
P & 0,26 & 0,28 & 0,34 \\
Proteína bruta & 11,00 & 11,50 & 12,00 \\
Extrato etéreo & 3,40 & 4,40 & 5,70 \\
Fibra bruta & 17,80 & 16,20 & 5,30 \\
Nutrientes digestíveis totais (estimado) & 70,94 & 73,80 & 82,20 \\
Fibra em detergente neutro & 54,00 & 66,60 & 58,00 \\
Fibra em detergente ácido & 24,20 & 25,80 & 22,80 \\
Matéria mineral & 3,20 & 3,20 & 3,30 \\
& & & \\
Cana-de-açúcar (volumoso) & 60,00 & 40,00 & 20,00 \\
Milho em grão moído & 26,33 & 50,51 & 61,43 \\
Farelo de algodão 38\% & 9,30 & 5,12 & 8,06 \\
Caroço de algodão & - & - & 6,99 \\
Ureia & 1,00 & 1,04 & - \\
Mistura mineral + monensina sódica & 3,37 & 3,33 & 3,52 \\
\hline
\end{tabular}

Fonte: Elaboração dos autores. 
Para avaliação econômica, consideraram-se cada proporção de concentrado na dieta como projetos de investimento mutuamente excludentes. Utilizou-se o método determinístico, assumindo valores fixos (conhecidos) para os itens que compõem os custos e indicadores de retorno e risco, tomando como base valores praticados em Goiás no ano de 2009 . O início do confinamento ocorreu no mês de agosto e a venda no mês de novembro, sendo acrescidos dois meses ao período de alimentação, para preparo das instalações e demais atividades antecedentes ao início da fase de alimentação.

Os custos de produção e indicadores financeiros foram determinados conforme metodologias propostas por Matsunaga et al. (1976), Resende Filho, Braga e Rodrigues (2001), Pacheco et al.
(2006), Kassai et al. (2007), Souza e Clemente (2009) e informações do ANUALPEC (2010).

Na Tabela 2 constam os valores dos coeficientes utilizados nas estimativas dos indicadores financeiros, enquanto que na Tabela 3, estão apresentadas as características de desempenho dos animais (SILVA, 2006), utilizadas na estimativa dos custos e indicadores financeiros.

A taxa mínima de atratividade (TMA) considerada mensalmente foi de 0,4868\% (correspondente ao rendimento da caderneta de poupança de $6 \%$ a.a.), justificada pelo fato do período de execução de cada projeto de investimento ser inferior a um ano, conforme sugestão de Resende Filho, Braga e Rodrigues (2001).

Tabela 2. Coeficientes utilizados nas estimativas dos indicadores financeiros da terminação em confinamento de novilhos recebendo diferentes proporções de concentrado na dieta.

\begin{tabular}{|c|c|}
\hline Itens & Coeficiente \\
\hline Tempo de preparo e uso do confinamento (meses) & 5,00 \\
\hline Taxa Mínima de Atratividade - TMA (\% a.m. $)^{1}$ & 0,4868 \\
\hline Instalações, máquinas, implementos, equipamentos $(\mathrm{R} \$ / \text { animal })^{2}$ & 100,00 \\
\hline Vida útil das instalações, máquinas, implementos, equipamentos (anos) & 10 \\
\hline Boi magro ( $\mathrm{R} \$$ a prazo -20 dias $/ \mathrm{kg}$ vivo $)^{3}$ & 2,68 \\
\hline Boi gordo ( $\mathrm{R} \$$ a prazo -20 a 30 dias $/ \mathrm{kg}$ vivo $)^{3}$ & 2,40 \\
\hline Boi gordo (R\$ a prazo - 20 a 30 dias/@ $)^{3}$ & 71,90 \\
\hline Salário mínimo nacional $(\mathrm{R} \$ / \mathrm{mês})^{3}$ & 465,00 \\
\hline Valor da terra - pastagem formada $(\mathrm{R} \$ / \mathrm{ha})^{3}$ & $4.500,00$ \\
\hline Volumoso $(\mathrm{R} \$ / \mathrm{t} \mathrm{MS})^{4}$ & 153,93 \\
\hline Concentrado $(\mathrm{R} \$ / \mathrm{t} \mathrm{MS})^{4}$ & 374,91 \\
\hline Mão-de-obra contratada + diarista $(\mathrm{R} \$ / \text { Homem dia })^{5}$ & 21,38 \\
\hline Assistência técnica (salários mínimos/mês) ${ }^{6}$ & 3 \\
\hline $\begin{array}{l}{ }^{1} \text { Considerou-se como referência o rendimento da Poupança ( } 6 \% \text { a.a.); TMA (\% } \\
{ }^{2} \text { Considerou-se a capacidade estática das instalações de } 1000 \text { bois. } \\
{ }^{3} \text { Obtido de ANUALPEC (2010). } \\
{ }^{4} \text { Alguns itens de custos obtidos de ANUALPEC (2010). } \\
{ }^{5} \text { Considerou-se } 1 \text { homem dia/300 bois confinados. } \\
{ }^{6} \text { Valor/1000 bois, considerando-se duas visitas mensais à propriedade. } \\
1 \text { R } \$=0,51 \text { US } \$ \text { (Média de cotações de agosto a novembro). } \\
\text { Fonte: Elaboração dos autores. }\end{array}$ & \\
\hline
\end{tabular}

O período de planejamento para depreciação das instalações foi de um ano, e para a depreciação de máquinas, implementos e equipamentos, o período foi coincidente com o número de meses estipulados para execução do projeto de investimento (cinco meses). Estimou-se valores médios para depreciações com instalações, máquinas, implementos e equipamentos de $\mathrm{R}$ \$ 0,027/animal/dia. 
Tabela 3. Características de desempenho dos animais de acordo com o nível de concentrado.

\begin{tabular}{|c|c|c|c|c|c|c|}
\hline \multirow[t]{2}{*}{ Características } & \multicolumn{3}{|c|}{ Nível de concentrado, $\%$ da MS } & \multirow[t]{2}{*}{ Média } & \multirow[t]{2}{*}{ CV $(\%)$} & \multirow[t]{2}{*}{$\mathrm{P}>\mathrm{F}$} \\
\hline & 40 & 60 & 80 & & & \\
\hline Peso inicial, $\mathrm{kg}$ & 349 & 347 & 349 & 348 & 9,6 & 0,9831 \\
\hline Peso final, $\mathrm{kg}$ & 441 & 446 & 462 & 449 & 8,8 & 0,4576 \\
\hline Ganho de peso, $\mathrm{kg}$ & 93 & 99 & 114 & 102 & 25,7 & 0,2209 \\
\hline $\mathrm{CMS}, \mathrm{kg} / \mathrm{animal} / \mathrm{dia}^{1}$ & 8,56 & 8,60 & 8,36 & 8,51 & 3,4 & 0,1765 \\
\hline
\end{tabular}

${ }^{1}$ Consumo de matéria seca (volumoso + concentrado).

Fonte: Silva (2006).

Os custos de oportunidade foram calculados considerando a TMA. O custo de oportunidade do capital investido foi obtido em relação ao somatório das despesas operacionais (compra animal magro, controle sanitário, alimentação volumoso + concentrado, mão-de-obra contratada/diarista + assistência técnica e outras), para o período correspondente ao número de meses estipulados para cada peso de abate. Para o custo de oportunidade da terra (confinamento + volumoso), considerou-se a possibilidade de arrendamento anual da mesma pelo equivalente a $3 \%$ do valor do hectare para cultura ( R\$ 4.500,00/ha), resultando em R\$ 0,51/ha/dia. Determinou-se para cada animal o uso de 0,05 ha multiplicado pelo período correspondente ao número de meses estipulados para cada peso de abate.

O custo com compra do animal magro (mês de agosto) e receita com venda do animal gordo (mês de novembro) foram estimados considerando as cotações praticadas no estado de Goiás, para pagamento a prazo (20 dias), no ano de 2009 (ANUALPEC, 2010).

O controle sanitário consistiu em aplicação de produto para controle de endo e ectoparasitas (ivermectina 1\%) e vacina contra febre aftosa. Ambas em dosagem por animal conforme recomendações dos fabricantes.

O custo com alimentação foi obtido pelo produto entre o consumo total de volumoso e concentrado (em kg MS/animal), pelos seus respectivos custos/ $\mathrm{kg}$ MS. O custo com volumoso incluiu as despesas com colheita e picagem da cana-de-açúcar.
Para as estimativas dos custos com mão-deobra (salário mínimo + encargos), para o período correspondente ao número de meses estipulados para cada peso de abate, considerou-se a necessidade de 1 homem/300 bois confinados para a mão-deobra contratada/diarista e três salários mínimos/ mês/1.000 animais para a mão-de-obra assistência técnica.

Outras despesas operacionais como manutenção de instalações, máquinas, implementos e equipamentos, combustível, energia elétrica, frete, impostos e alimentação da mão-de-obra foram estimadas pelo equivalente a $2,5 \%$ das despesas operacionais citadas anteriormente para estimar o custo de oportunidade do capital investido.

O custo operacional efetivo (COE) foi obtido pelo somatório das despesas operacionais: compra do animal magro, controle sanitário, alimentação com volumoso + concentrado, mão-de-obra contratada/diarista + assistência técnica e outras despesas operacionais. O custo operacional total (COT) representou o somatório do COE e depreciações. A margem bruta foi calculada como: Receita com venda do animal gordo (R) - COE. A margem líquida foi obtida da seguinte maneira: $\mathrm{R}$ - COT. O lucro foi calculado como: R - (Fixos + Variáveis, ou COT + oportunidades). O custo/kg de ganho de peso foi estimado pela razão entre o custo total e o peso final, e o custo/@ foi estimado pela razão entre o custo total e o peso final/30.

Os indicadores financeiros estimados foram: margem bruta (MB) em $\mathrm{R} \$$; margem líquida 
(ML) em R\$; lucro em R\$; valor presente líquido (VPL) em R\$; índice benefício:custo (IB:C) ou índice de lucratividade; Retorno adicional sobre o investimento (ROIA) ou taxa de rentabilidade em $\%$; taxa interna de retorno (TIR) em \% ao mês; período de recuperação do investimento (payback) descontado (PAYBACKd) em meses; e relação TMA:TIR. Com exceção de MB, ML e lucro, os demais indicadores não incluíram os custos de oportunidades na estimativa do custo total.

O delineamento experimental foi o inteiramente casualizado, com três tratamentos e dez repetições. Os dados foram submetidos à análise de regressão linear simples e teste da falta de ajuste (lack-offit), a 5\% de significância. O modelo matemático utilizado na análise de regressão foi o seguinte: $\hat{y}_{\mathrm{ij}}$ $=\mathrm{b}_{\mathrm{o}}+\mathrm{b}_{1} \mathrm{NC}_{\mathrm{i}}+\mathrm{e}_{\mathrm{ij}}$, onde: $\hat{\mathrm{y}}_{\mathrm{ij}}=$ variáveis dependentes estimadas, $b_{0}=$ intercepto, $b_{1}=$ coeficiente de regressão ou angular, $\mathrm{NC}_{\mathrm{i}}=$ nível de concentrado na $\operatorname{dieta}(\%), \mathrm{e}_{\mathrm{ij}}=$ erro aleatório $\left(\sim \mathrm{NID}, 0, \sigma^{2}\right)$.

\section{Resultados e Discussão}

Houve aumento no custo estimado/kg MS da dieta com o incremento no nível de concentrado (Tabela 4), representando diferença de $48 \%$ do menor para o maior nível. Nota-se que a fração mais representativa deste custo/kg de MS foi o concentrado, em todos os tratamentos testados, correspondendo a 60,5 , 78,0 e $91,3 \%$, respectivamente, para 40,60 e $80 \%$ de concentrado na dieta.

Tabela 4. Demonstração do custo da dieta experimental de acordo com o nível de concentrado.

\begin{tabular}{lccc}
\hline \multicolumn{1}{c}{ Ingredientes da dieta } & \multicolumn{3}{c}{ Nível de concentrado, \% da MS } \\
\cline { 2 - 3 } & 40 & 60 & 80 \\
\hline & & R $\$$ kg MS & 0,03 \\
Volumoso $^{1}$ & 0,09 & 0,06 & 0,31 \\
Concentrado $^{2}$ & 0,14 & 0,21 & 0,34 \\
Total & 0,23 & 0,27 & 8,7 \\
& & $\%$ do total \\
Volumoso $^{1}$ & 39,5 & 22,0 & 91,3 \\
Concentrado $^{2}$ & 60,5 & 78,0 & \\
\hline
\end{tabular}

${ }^{1}$ Cana-de-açúcar in natura picada.

${ }^{2}$ Concentrado comercial.

$1 \mathrm{R} \$=0,51$ US\$.

Fonte: Elaboração dos autores.

Diversos estudos envolvendo terminação de bovinos de corte relatam o item concentrado como sendo proporcionalmente mais oneroso em relação ao item volumoso (PACHECO et al., 2006; RESTLE et al., 2007; MISSIO et al., 2009). Embora atualmente exista a tendência de incremento na proporção de concentrado da dieta oferecida nos grandes confinamentos do país, pode-se considerar que, em média, pelo menos $2 / 3$ do custo total da dieta seria relativo ao concentrado. Com isso, fica evidente a importância das estratégias de comercialização (VAZ; VAZ; ROSO, 2000) no momento da aquisição dos ingredientes componentes do concentrado, como por exemplo a época do ano e quantidade adquirida. Além disso, Pacheco et al. (2006) abordam a importância do uso de volumoso de melhor qualidade, visando substituir parte dos nutrientes fornecidos pelo concentrado, reduzindo o custo total da dieta. 
Verifica-se que os custos fixos estimados por animal (Tabela 5) somaram $\mathrm{R} \$ 13,21$, sendo a depreciação com instalações, máquinas, implementos e equipamentos o item de maior representatividade (74,6\%). Este item de custo fixo pode apresentar grande variação de um sistema de terminação em confinamento para outro, devido às várias possibilidades de maximização do uso das máquinas, implementos e equipamentos, assim como da estrutura física da instalação. Por exemplo, o custo com instalação poderia ser minimizado com uso de piso de chão batido e cercas convencionais.

Tabela 5. Médias para itens componentes dos custos e receitas estimados por animal, de acordo com o nível de concentrado na dieta.

\begin{tabular}{|c|c|c|c|c|c|}
\hline \multirow{2}{*}{ Itens } & \multicolumn{3}{|c|}{ Nível de concentrado, $\%$ da MS } & \multirow{2}{*}{ CV $(\%)$} & \multirow{2}{*}{ Valor $\mathrm{P}^{1}$} \\
\hline & 40 & 60 & 80 & & \\
\hline Custos Fixos (R\$) & 13,21 & 13,21 & 13,21 & - & - \\
\hline Depreciação $(\mathrm{R} \$)^{2}$ & 9,86 & 9,86 & 9,86 & - & - \\
\hline Oportunidade $(\mathrm{R} \$)^{2}$ & 0,58 & 0,58 & 0,58 & - & - \\
\hline Oportunidade da terra $(\mathrm{R} \$)$ & 2,77 & 2,77 & 2,77 & - & - \\
\hline Custos Variáveis $(\mathrm{R} \$)^{3}$ & 1187,18 & 1218,82 & 1275,81 & 7,9 & 0,0499 \\
\hline Compra do animal magro $(\mathrm{R} \$)$ & 933,98 & 928,35 & 935,32 & 9,4 & 0,9731 \\
\hline Controle sanitário (R\$) & 3,59 & 3,58 & 3,59 & 5,5 & 0,9731 \\
\hline Alimentação volumoso $(\mathrm{R} \$)^{4}$ & 69,37 & 46,42 & 22,56 & 4,8 & 0,0001 \\
\hline Alimentação concentrado $(\mathrm{R} \$)^{5}$ & 106,09 & 164,82 & 235,98 & 4,7 & 0,0001 \\
\hline Mão-de-obra contratada/diarista (R\$) & 10,69 & 10,69 & 10,69 & - & - \\
\hline Assistência técnica (R\$) & 6,98 & 6,98 & 6,98 & - & - \\
\hline Outros $(\mathrm{R} \$)^{6}$ & 28,27 & 29,02 & 30,38 & 7,9 & 0,0499 \\
\hline Oportunidade do capital investido $(\mathrm{R} \$)^{7}$ & 28,21 & 28,96 & 30,31 & 7,9 & 0,0499 \\
\hline Custo Total (Fixos + Variáveis) $(\mathrm{R} \$)^{8}$ & 1200,39 & 1232,03 & 1289,03 & 7,8 & 0,0499 \\
\hline Receita com venda do animal gordo (R) (R\$) & 1057,89 & 1068,43 & 1108,70 & 8,6 & 0,2325 \\
\hline Custo/kg de ganho de peso ( $\mathrm{R} \$ / \mathrm{kg})$ & 2,72 & 2,77 & 2,80 & 6,1 & 0,3190 \\
\hline Custo/@(R\$/@) & 81,68 & 83,03 & 83,97 & 6,1 & 0,3190 \\
\hline Custo Operacional Efetivo (COE) $(\mathrm{R} \$)^{9}$ & 1158,97 & 1189,86 & 1245,50 & 7,9 & 0,0499 \\
\hline Custo Operacional Total $(\mathrm{COT})(\mathrm{R} \$)^{10}$ & 1168,83 & 1199,72 & 1255,36 & 7,8 & 0,0499 \\
\hline
\end{tabular}

${ }^{1}$ efeito de ordem linear relativo ao aumento no peso de abate.

${ }^{2}$ instalações, máquinas, implementos e equipamentos.

${ }^{3} \hat{Y}=1094,30-2,216^{*} \mathrm{NC}\left(\mathrm{R}^{2}=0,1304\right)$.

${ }^{4} \hat{\mathrm{Y}}=116,33-1,170 * \mathrm{NC}\left(\mathrm{R}^{2}=0,9877\right) .{ }^{5} \hat{\mathrm{Y}}=-25,87+3,247 * \mathrm{NC}\left(\mathrm{R}^{2}=0,9794\right)$.

${ }^{6} \hat{\mathrm{Y}}=26,06+0,053 * \mathrm{NC}\left(\mathrm{R}^{2}=0,1304\right) .{ }^{7} \hat{\mathrm{Y}}=26,00+0,053 * \mathrm{NC}\left(\mathrm{R}^{2}=0,1304\right)$.

${ }^{8} \hat{\mathrm{Y}}=1107,52+2,216 * \mathrm{NC}\left(\mathrm{R}^{2}=0,1304\right) .{ }^{9} \hat{\mathrm{Y}}=1068,30+2,163 * \mathrm{NC}\left(\mathrm{R}^{2}=0,1304\right)$.

${ }^{10} \hat{\mathrm{Y}}=1078,17+2,163 * \mathrm{NC}\left(\mathrm{R}^{2}=0,1304\right)$.

$1 \mathrm{R} \$=0,51 \mathrm{US} \$$.

Fonte: Elaboração dos autores.

Dos oito itens componentes dos custos variáveis, houve variação significativa apenas para alimentação volumosa e concentrada, outros e oportunidade do capital investido (Tabela 5). Em relação aos dois primeiros itens, com o incremento no teor de concentrado na dieta de 40 para $80 \%$, o custo com volumoso (cana-de-açúcar in natura picada) reduziu $\mathrm{R} \$ 1,17$, enquanto o custo com concentrado aumentou R\$3,25, representando diferença de 67 e 122\%, respectivamente, do menor para o maior nível de concentrado. Estas diferenças são explicadas pela similaridade no consumo de 
matéria seca (CMS) (Tabela 3) e o incremento da participação do concentrado relativo ao custo da dieta (Tabela 4). Outros e oportunidade do capital investido apresentaram incremento linear com o aumento no nível de concentrado, no entanto, com pouca variação estimada por animal. Para os demais itens, os valores foram similares pelo fato do peso inicial e o período de alimentação ser os mesmos nos tratamentos testados.

A diferença significativa no custo total entre os níveis de concentrado é reflexo da diferença nos custos variáveis, resultante principalmente das variações no custo com volumoso e com concentrado. Através deste resultado, seria esperada diferença no custo de produção por kg de ganho de peso ou por@, no entanto, aspecto interessante ocorrido foi a similaridade nos mesmos, com o aumento no nível de concentrado na dieta. Em nenhum dos tratamentos o $\mathrm{kg}$ do boi gordo superou o custo de produção, tornando inviável a terminação em confinamento, de acordo com o peso de abate estipulado $(\sim 450 \mathrm{~kg})$ e/ou período de alimentação total (90 dias). Ainda assim, é importante ressaltar que o confinamento pode representar uma estratégia viável quando incluída em um planejamento global de um sistema de produção de bovinos de corte, apresentando vantagens diretas e/ou indiretas relevantes (redução na idade de abate, liberação de áreas de pastagens para outras categorias, melhoria na qualidade de carcaça e carne). No entanto, no presente estudo, o objetivo foi o de avaliar a tecnologia isoladamente, informando uma maneira metodológica auxiliadora na tomada de decisão entre investir ou não nesta tecnologia.

Quanto aos valores percentuais da participação relativa dos itens componentes do custo (Tabela 6), verifica-se que quando avaliado em relação ao custo total, nota-se expressiva participação dos custos variáveis (média de 98,94\%), sendo que os itens mais representativos foram, em ordem decrescente, compra do animal magro (média de 75,24\%), alimentação concentrado (média de 13,51\%) e alimentação volumosa (média de 3,77\%). Estes três itens somados representaram $92,52 \%$ do custo total. Nota-se que para os dois últimos itens, houve redução na participação relativa com volumoso e incremento com a de concentrado, com o aumento no nível de concentrado da dieta oferecida aos animais. Em estudos que utilizaram metodologia semelhante ao do presente estudo, os resultados são concordantes, ou seja, maiores participações relativas dos itens compra do animal magro e alimentação volumoso+concentrado, conforme demonstrado em Restle et al. (2007) trabalhando com novilhos superjovens Red Angus abatidos com diferentes pesos $(340,373,401$ ou $434 \mathrm{~kg})$ - obteve lucro em todos os pesos, e Missio et al. (2009) avaliando tourinhos superjovens cruzados Charolês $\mathrm{x}$ Nelore alimentados com dietas contendo diferentes níveis de concentrado $(22,40,59$ ou $79 \%$ ) - obteve prejuízo somente no maior nível. Nestes dois últimos estudos, a alimentação inclusive superou o custo com aquisição dos animais magros a partir dos 401 kg (144 dias de alimentação) e 59\% de concentrado, respectivamente. Resultados concordantes também foram relatados por Lopes e Magalhães (2005) - obteve lucro, que ao avaliarem a terminação de 3.583 animais no oeste de Minas Gerais em confinamento, verificaram que os componentes do custo operacional efetivo que exerceram maior influência sobre os custos da atividade estudada foram, em ordem decrescente: aquisição de animais $(68,4 \%)$, alimentação $(22,3 \%)$, despesas diversas, mão-de-obra, sanidade e impostos.

Quando a participação dos itens de custo foi apresentada em relação ao custo total-compra do animal (ou custo parcial), pode-se notar que em média, a alimentação (volumoso + concentrado) representou em média $69,51 \%$ dos custos variáveis, seguido por outros (média de 9,59\%) e oportunidade do capital investido (média de 9,56\%). As maiores variações de acordo com o incremento no nível de concentrado na dieta foram verificadas para o primeiro item citado, com redução de $75 \%$ (26,04 para 6,38\%) para alimentação volumosa e aumento de 68\% (39,82 para $66,72 \%$ ) para alimentação concentrado. Demais 
estudos apresentam participações relativas dos custos parciais concordantes com o presente estudo, como os de Pacheco e al. (2006) trabalhando com $40 \%$ de concentrado e Restle et al. (2007) trabalhando com
$44 \%$ de concentrado, sendo os mais representativos volumoso, concentrado, fornecimento da alimentação, oportunidade do capital investido e confecção do concentrado.

Tabela 6. Participação relativa dos itens componentes do custo expresso em relação ao custo total e custo total menos o custo com a compra do animal magro (parênteses), de acordo com o nível de concentrado na dieta.

\begin{tabular}{lrrrr}
\hline \multirow{2}{*}{ Variável } & \multicolumn{2}{c}{ Nível de concentrado, \% da MS } & \multirow{2}{*}{ Média } \\
\cline { 2 - 3 } & \multicolumn{1}{c}{40} & \multicolumn{1}{c}{60} & \multicolumn{1}{c}{80} & \\
\hline Custo total (R\$) & 1200,39 & 1232,03 & 1289,03 & 1240,48 \\
Custo total - compra do animal magro (R\$) & 266,41 & 303,68 & 353,71 & 307,93 \\
Custos fixos (\%) & $1,1(5,0)$ & $1,1(4,4)$ & $1,0(3,7)$ & $1,1(4,4)$ \\
Depreciação1 (\%) & $0,8(3,7)$ & $0,8(3,3)$ & $0,8(2,8)$ & $0,8(3,3)$ \\
Oportunidade1 (\%) & $0,05(0,2)$ & $0,05(0,2)$ & $0,04(0,2)$ & $0,05(0,2)$ \\
Oportunidade da terra (\%) & $0,2(1,0)$ & $0,2(0,9)$ & $0,2(0,8)$ & $0,2(0,9)$ \\
Custos variáveis (\%) & $98,9(95,0)$ & $98,9(95,7)$ & $99,0(96,3)$ & $98,9(96,0)$ \\
Compra animal magro (\%) & $77,8(-)$ & $75,4(-)$ & $72,6(-)$ & $75,2(-)$ \\
Controle sanitário (\%) & $0,3(1,4)$ & $0,3(1,2)$ & $0,3(1,0)$ & $0,3(1,2)$ \\
Alimentação volumoso (\%) & $5,8(26,0)$ & $3,8(15,3)$ & $1,8(6,4)$ & $3,8(15,9)$ \\
Alimentação concentrado (\%) & $8,8(39,8)$ & $13,4(54,3)$ & $18,3(66,7)$ & $13,5(53,6)$ \\
Alimentação (volumoso + concentrado) (\%) & $14,6(65,9)$ & $17,2(69,6)$ & $20,1(73,1)$ & $17,3(69,5)$ \\
Mão-de-obra contratada/diarista (\%) & $0,9(4,0)$ & $0,9(3,5)$ & $0,8(3,0)$ & $0,9(3,5)$ \\
Assistência técnica (\%) & $0,6(2,6)$ & $0,6(2,3)$ & $0,5(2,0)$ & $0,6(2,3)$ \\
Outros (\%) & $2,4(10,6)$ & $2,4(9,6)$ & $2,4(8,6)$ & $2,4(9,6)$ \\
Oportunidade do capital investido (\%) & $2,4(10,6)$ & $2,4(9,6)$ & $2,4(8,6)$ & $2,4(9,6)$ \\
\hline
\end{tabular}

${ }^{1}$ instalações, máquinas, implementos e equipamentos. $1 \mathrm{R} \$=0,51 \mathrm{US} \$$.

Fonte: Elaboração dos autores.

Com isso, evidencia-se a relevância prioritária quanto às estratégias de comercialização, referente à aquisição do animal magro e itens da dieta oferecida aos animais, a influenciar em maior proporção o custo total de produção. Assim, o monitoramento de cotações ao longo do(s) ano(s) pode, por exemplo, auxiliar na tomada de decisão deste sistema de terminação. Esta afirmação ficou comprovada no estudo de Resende Filho, Braga e Rodrigues (2001), que ao avaliarem três sistemas de terminação em confinamento no estado de Minas Gerais, considerando uma mesma instalação, épocas distintas de venda e o nível de utilização da capacidade instalada. Concluíram que o início do confinamento em outubro e comercialização em dezembro foi o pior sistema, devido aos maiores custos dos fatores de produção na época inicial (outubro) e menores coações do boi gordo na época de venda (dezembro).

Os indicadores financeiros (Tabela 7) demonstraram prejuízo econômico independentemente do nível de concentrado utilizado. 
Tabela 7. Indicadores financeiros de acordo com o nível de concentrado na dieta, estimados por animal e apenas durante o período de confinamento.

\begin{tabular}{|c|c|c|c|c|c|c|}
\hline \multirow{2}{*}{ Indicadores } & \multicolumn{3}{|c|}{ Nível de concentrado, $\%$ da MS } & \multirow{2}{*}{ Média } & \multirow{2}{*}{ CV $(\%)$} & \multirow{2}{*}{ Valor P } \\
\hline & 40 & 60 & 80 & & & \\
\hline TMA $(\% \text { a.m. })^{1}$ & 0,4868 & 0,4868 & 0,4868 & - & - & - \\
\hline $\mathrm{N}^{\mathrm{o}}$ períodos (meses) & 5 & 5 & 5 & - & - & - \\
\hline Margem Bruta (R - COE) (R\$) & $-101,08$ & $-121,42$ & $-136,80$ & $-119,77$ & 57,1 & 0,2529 \\
\hline Margem Líquida (R - COT) (R\$) & $-110,94$ & $-131,29$ & $-146,67$ & $-129,63$ & 52,8 & 0,2529 \\
\hline Lucro (R - Custo Total) (R\$) & $-142,50$ & $-163,60$ & $-180,33$ & $-162,14$ & 42,8 & 0,2327 \\
\hline VPL (R\$) & $-125,50$ & $-145,56$ & $-160,98$ & $-144,01$ & 46,9 & 0,2505 \\
\hline IB:C & 0,9133 & 0,8981 & 0,8868 & 0,8994 & 6,0 & 0,2844 \\
\hline ROIA (\%) & $-8,67$ & $-10,19$ & $-11,32$ & $-10,06$ & 53,9 & 0,2844 \\
\hline TIR (\% a.m.) & $-3,27$ & $-3,88$ & $-4,37$ & $-3,84$ & 52,7 & 0,2364 \\
\hline TMA:TIR & 0,2409 & 0,0223 & 0,1479 & 0,1370 & 102,5 & 0,3122 \\
\hline PAYBACKd (meses) & 5,49 & 5,59 & 5,66 & 5,58 & 6,1 & 0,2745 \\
\hline
\end{tabular}

${ }^{1}$ Taxa mínima de atratividade equivalente a $6 \%$ a.a.

${ }^{1}$ efeito de ordem linear relativo ao aumento no peso de abate.

$1 \mathrm{R} \$=0,51$ US\$.

Fonte: Elaboração dos autores.

A margem bruta, margem líquida e o lucro são informações "tradicionais" relacionadas com o retorno do investimento, o que conforme Simões, Moura e Rocha (2006) indicam a possibilidade de viabilidade econômica no curto, médio e longo prazo, respectivamente. No curto prazo quando considera a diferença entre a receita e as despesas operacionais, o que se torna muito relevante em investimentos como a terminação em confinamento, pois o ciclo de cada lote de animais (entrada quando magro até a saída quando gordo) é menor do que um ano. No médio prazo quando considera a diferença entre a receita e as despesas operacionais + depreciações, sendo também importante, pois as depreciações relacionadas com instalações, máquinas e implementos têm vida útil de alguns anos. No longo prazo quando considera a diferença entre a receita e as despesas operacionais + depreciações + oportunidades, que adicionalmente considera o valor do dinheiro no tempo.

Avaliando alguns indicadores econômicos em sistemas de cria, recria e engorda, Simões, Moura e Rocha (2006) estimaram valores positivos apenas para margem bruta em sistema de terminação em semi-confinamento, concluindo que o investimento neste sistema foi menos atrativo que outra atividade que remunere o capital em $6 \%$ ao ano. No trabalho de Rodrigues Filho et al. (2002), os diferentes níveis de concentrado e cama de frango testados resultaram em lucro negativo para a terminação de bovinos de origem leiteira, quando o preço de venda da carne produzida foi igual ao preço do boi gordo. No entanto, ao simular o incremento em $10 \%$ no preço de venda da carne produzida, mantendo os mesmos custos, todos os tratamentos apresentaram lucro. Missio et al. (2009) simularam preços do custo com concentrado em porcentagem do preço do $\mathrm{kg}$ do boi gordo $(20,26,36$ e 53\%) e verificaram que ocorreu diminuição linear da renda líquida e lucratividade com o aumento do concentrado na dieta. Nos maiores níveis de concentrado, a terminação dos animais foi inviabilizada economicamente quando o preço do concentrado atingiu cerca $26 \%$ do preço do boi gordo e, quando o preço do concentrado representou $53 \%$ do valor do preço do boi gordo, todos os níveis de concentrado utilizados se tornaram economicamente inviáveis.

Quanto ao Valor presente líquido, que representa 
o quanto se recupera do investimento inicial, considerando sua remuneração quando aplicado na taxa mínima de atratividade - Taxa mínima de atratividade (SOUZA; CLEMENTE, 2009), os valores negativos estimados indicam que qualquer um dos três investimentos não resultou em excedente monetário, onde vale ressaltar os expressivos valores negativos estimados. No estudo de Resende Filho, Braga e Rodrigues (2001), que avaliou sistemas de terminação em confinamento variando a época de comercialização, os autores estimaram Valor presente líquido positivos, demonstrando que a engorda intensiva no estado de Minas Gerais, visando incrementar a produção de carne, é viável economicamente.

$\mathrm{O}$ índice benefício:custo ou índice de lucratividade representa a proporção entre os valores presentes das receitas e dos custos, ou seja, o quanto se espera de retorno a cada $\mathrm{R} \$ 1,00$ investido. Conforme estimativas, no presente estudo nenhum valor foi superior a 1 , demonstrando a inviabilidade de retorno do investimento para os diferentes níveis de concentrado. Isto ocorre quando o fluxo de saídas descontado é maior do que o fluxo de entradas descontado. Avaliando o índice benefício:custo da terminação em confinamento de bovinos F1 Angus $\mathrm{x}$ Nelore, e Blonde D'Aquitaine x Nelore abatidos com 480, 520 ou $560 \mathrm{~kg}$, Mello et al. (2009) relataram interação significativa entre grupo racial e peso de abate, no entanto, houve redução linear no índice benefício:custo com o aumento no peso de abate, sendo de 1,83, 0,97 e 0,95, respectivamente, o que está relacionado com o aumento no tempo de alimentação.

O indicador Retorno Adicional sobre o Investimento, também conhecido como taxa de rentabilidade (\%) ou valor econômico agregado (KASSAI et al., 2007), é apontado por Souza e Clemente (2009) como eficiente indicador de rentabilidade de um projeto de investimento. No presente estudo, os valores médios estimados foram negativos, oscilando entre $-8,67$ e $-11,32 \%$, respectivamente, para os níveis de 40 e $80 \%$ de concentrado.
Em nenhum dos níveis de concentrado avaliados a Taxa interna de retorno foi superior à Taxa mínima de atratividade, portanto, demonstrando elevado risco do investimento. A Taxa interna de retorno é a taxa que torna o Valor presente líquido igual a zero, portanto o retorno do investimento seria nulo e negativo caso a Taxa interna de retorno fosse igual ou menor que a Taxa mínima de atratividade, respectivamente (KASSAI et al., 2007).

Para a relação Taxa mínima de atratividade:Taxa interna de retorno, quanto mais próximos forem os valores da Taxa interna de retorno e Taxa mínima de atratividade, menor será o Valor presente líquido. Assim, de acordo com esta relação, quanto mais próximo a relação Taxa mínima de atratividade:Taxa interna de retorno for de um, maior o risco do Valor presente líquido ser zero e menor a chance de retorno. No presente estudo, este indicador também demonstrou elevado risco para os níveis de concentrado avaliados.

Alguns estudos avaliaram a resposta econômica do confinamento de bovinos quanto à Taxa interna de retorno, como os de Fernandes et al. (2007) e Coan et al. (2008). Avaliando machos e fêmeas Canchim em confinamento alimentados com dietas à base de silagem de milho e concentrado ou cana-de-açúcar e concentrado contendo grãos de girassol, Fernandes et al. (2007) concluíram que a dieta com silagem de milho mostrou-se economicamente mais viável para terminação de bovinos jovens em confinamento $(5,98$ vs $1,46 \%$ a.m.) e os machos não-castrados foram os mais adequados para exploração de bovinos jovens em confinamento, independentemente da dieta. Os autores consideraram o rendimento da poupança $(0,63 \%$ a.m. $)$ como referência, pelo fato de ser a aplicação financeira mais comum. Já Coan et al. (2008), que estudaram a viabilidade econômica, desempenho e características de carcaça de garrotes em confinamento alimentados com dietas contendo silagem de capins tanzânia ou marandu ou silagem de milho, concluíram que a taxa interna de retorno foram maiores nos animais alimentados com as dietas contendo silagem de milho (entre 11 e $12 \%$ 
a.m.), superior às aplicações.

Quanto ao payback descontado para a Taxa mínima de atratividade, que avalia o prazo de recuperação do capital investido considerando o valor do dinheiro no tempo (KASSAI et al., 2007), as estimativas foram superiores ao período total de execução dos projetos (5 meses), demonstrando risco elevado. Souza e Clemente (2009) comentam que à medida que o payback se aproxima do final do horizonte de planejamento, maior é o risco.

Espera-se que para este sistema de terminação os valores de payback descontado sejam próximos ou iguais ao número de períodos para execução do projeto de investimento, pois a receita obtida com a comercialização dos animais gordos coincide com o último período. No entanto, valores superiores ao período final de execução são evidências de que as chances de prejuízo são grandes.

Nota-se na Tabela 7, expressivos valores dos coeficientes de variação para a maioria dos indicadores financeiros, demonstrando variações acentuadas nas estimativas dos mesmos e relação linear marcante, conforme se alteraram os níveis de concentrado na dieta.

Analisando os indicadores financeiros estimados, houve inviabilidade econômica da terminação em confinamento, independente do nível de concentrado utilizado na dieta. Houve concordância entre os indicadores estimados, demonstrando sua relevância na tomada de decisão. O uso do confinamento unicamente como alternativa de terminação representou alternativa de baixo retorno e alto risco.

\section{Referências}

ANUÁRIO DA PECUÁRIA BRASILEIRA ANUALPEC. São Paulo: Informa Economics FNP, $2010.360 \mathrm{p}$.

COAN, R. M.; REIS, R. A.; RESENDE, F. D.; SAMPAIO, R. L.; SCHOCKEN-ITURRINO, R. P.; GARCIA, G. R.; BERCHIELLI, T. T. Viabilidade econômica, desempenho e características de carcaça de garrotes em confinamento alimentados com dietas contendo silagem de capins tanzânia ou marandu ou silagem de milho. Revista Brasileira de Zootecnia, Viçosa, MG, v. 37, n. 2, p. 311-318, 2008.

FERNANDES, A. R. M.; SAMPAIO, A. A. M.; HENRIQUE, W.; PERECIN, D.; OLIVEIRA, E. A.; TÚLLIO, R. R. Avaliação econômica e desempenho de machos e fêmeas Canchim em confinamento alimentados com dietas à base de silagem de milho e concentrado ou cana-de-açúcar e concentrado contendo grãos de girassol. Revista Brasileira de Zootecnia, Viçosa, MG, v. 36, n. 4, p. 855-864, 2007.

KASSAI, J. R.; CASANOVA, S. P. C.; SANTOS, A.; ASSAF NETO, A. Retorno de investimento: abordagens matemática e contábil do lucro empresarial. 3. ed. São Paulo: Atlas, 2007. 277 p.

KÖPPEN, W. Climatologia tradicional. Traduzida para o Espanhol por Pedro Henchiehs Pérez. México: Fondo de Cultura Econômica, 1948. 479 p.

LOPES, M. A.; MAGALHÃES, G. P. Análise da rentabilidade da terminação de bovinos de corte em condições de confinamento: um estudo de caso. Arquivo Brasileiro de Medicina Veterinária e Zootecnia, Belo Horizonte, MG, v. 57, n. 3, p. 374-379, 2005.

MATSUNAGA, M.; BEMELMANS, P. F.; TOLEDO, P. E. N.; DULLEY, R. D.; OKAWA, H.; PEDROSO, I. A. Metodologia de custo utilizada pelo IEA. Agricultura em São Paulo, São Paulo, v. 23, n. 1, p. 123-139, 1976.

MELLO, R.; RESENDE, F. D.; QUEIROZ, A. C.; FARIA, M. H.; OLIVEIRA, A. S.; SIQUEIRA, G. R. Bio-economicity of the finishing phase on feedlot of crossbred young bulls slaughtered at different body weights. Revista Brasileira de Zootecnia, Viçosa, MG, v. 38, n. 1, p. 109-121, 2009.

MILLEN, D. D.; PACHECO, R. D. L.; ARRIGONI, M. D. B.; GALYEAN, M. L.; VASCONCELOS, J. T. A snapshot of management practices and nutritional recommendations used by feedlot nutritionists in Brazil. Journal of Animal Science, Champaign, v. 87, n. 10, p. 3427-3439, 2009.

MISSIO, R. L.; BRONDANI, I. L.; FREITAS, L. S.; SACHET, R. H.; SILVA, J. H. S.; RESTLE, J. Desempenho e avaliação econômica da terminação de tourinhos em confinamento alimentados com diferentes níveis de concentrado na dieta. Revista Brasileira de Zootecnia, Viçosa, MG, v. 38, n. 7, p. 1309-1316, 2009.

PACHECO, P. S.; RESTLE, J.; VAZ, F. N.; FREITAS, A. K.; PADUA, J. T.; NEUMANN, M.; ARBOITTE, M. $Z$. Avaliação econômica da terminação em confinamento de novilhos jovens e superjovens de diferentes grupos 
genéticos. Revista Brasileira de Zootecnia, Viçosa, MG, v. 35, n. 1, p. 309-320, 2006.

RESENDE FILHO, M. A.; BRAGA, M. J.; RODRIGUES, R. V. Sistemas de terminação em confinamento: perspectivas para dinamização da cadeia produtiva da carne bovina em Minas Gerais. Revista Brasileira de Economia, Rio de Janeiro, v. 55, n. 1, p. 107-131, 2001.

RESTLE, J.; PACHECO, P. S.; COSTA, E. C.; FREITAS, A. K.; VAZ, F. N.; BRONDANI, I. L.; FERNANDES, J. J. R. Apreciação econômica da terminação em confinamento de novilhos Red Angus superjovens abatidos com diferentes pesos. Revista Brasileira de Zootecnia, Viçosa, MG, v. 36, n. 4, p. 978-986, 2007.

RESTLE, J.; VAZ, F. N. Eficiência e qualidade na produção de carne bovina. In: REUNIÃO ANUAL DA SOCIEDADE BRASILEIRA DE ZOOTECNIA, 40., 2003, Santa Maria. Anais... Santa Maria: Sociedade Brasileira de Zootecnia, 2003. 1 CD-ROM.

RESTLE, J.; VAZ, F. N.; PACHECO, P. S. Uso de animais zebuínos em cruzamentos de bovinos de corte no sul do Brasil. In: SIMPÓSIO BRASILEIRO SOBRE CRUZAMENTO DE BOVINOS DE CORTE, 1., 2004, Londrina. Anais... Londrina: IAPAR, 2004. 1 CD-ROM.
RODRIGUES FILHO, M.; MANCIO, A. B.; GOMES, S. T.; GOMES, S. T.; SILVA, F. F.; LANA, R. P.; RODRIGUES, N. E. B.; SOARES, C. A.; VELOSO, C. M. Avaliação econômica do confinamento de novilhos de origem leiteira, alimentados com diferentes níveis de concentrado e de cama de frango. Revista Brasileira de Zootecnia, Viçosa, MG, v. 31, n. 5, p. 2055-2069, 2002.

SILVA, R. M. Diferentes niveis de energia sobre o desempenho e características de carcaça de novilhos mestiços Nelore confinados com cana-de-açúcar. 2006. Dissertação (Mestrado em Produção Animal) - Escola de Veterinária, Universidade Federal de Goiás, Goiânia.

SIMÕES, A. R. P.; MOURA, A. D.; ROCHA, D. T. Avaliação econômica comparativa de sistemas de produção de gado de corte sob condições de risco no Mato Grosso do Sul. Revista de Economia e Agronegócio, Viçosa, MG, v. 5, n. 1, p. 51-72, 2006.

SOUZA, A.; CLEMENTE, A. Decisões financeiras e análise de investimentos. 6. ed. São Paulo: Atlas, 2009. $186 \mathrm{p}$.

VAZ, F. N.; VAZ, R. Z.; ROSO, C. Tipos e níveis de concentrado para o confinamento. In: RESTLE, J. (Ed.). Eficiência na produção de bovinos de corte. Santa Maria: Universidade Federal de Santa Maria, 2000. p. 219-257. 
